\title{
O crime biológico: implicações para a sociedade e para o sistema de justiça criminal
}

\author{
The biological crime: implications for society and the \\ criminal justice system
}

\begin{abstract}
Adrian Raine*
* Departamentos de Criminologia, Psiquiatria e Psicologia, University of Pennsylvania, Filadélfia, EUA. E-mail: araine@sas.upenn.edu
\end{abstract}

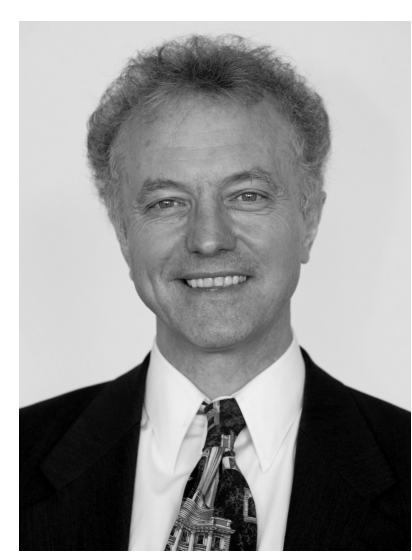

As últimas duas décadas testemunharam uma revolução em nosso entendimento da mente criminal. Por quase um século, culpamos a pobreza, a desigualdade social e as más companhias como os principais causadores de crimes. É quase certo que esses fatores desempenhem um papel relevante, porém a novidade no século XXI é o aumento do reconhecimento de que fatores genéticos e neurobiológicos são igualmente importantes na modelagem do comportamento criminoso. Os desafios que enfrentamos à luz desses novos achados são múltiplos, incluindo como vamos abordar os transtornos neurológicos em infratores violentos e quais são as implicações para as subdisciplinas emergentes de neurodireito e neuroética.

\section{Genes e crime}

Hoje há poucas dúvidas científicas de que os genes desempenham papel significativo no comportamento antisocial. Revisões de mais de 100 análises de estudos com gêmeos e de estudos de adoção oferecem evidências claras de que cerca de $50 \%$ da variação no comportamento anti-social são atribuíveis a influências genéticas ${ }^{1}$. A área está agora se movendo para uma questão mais importante, de terceira geração: "Quais genes predispõem a quais tipos de comportamento anti-social?". Respostas iniciais estão começando a surgir a partir de estudos de genética molecular. Quando é realizado o knockout do gene da monoamina-oxidase A(MAO-A) em camundongos, estes se tornam altamente agressivos. Se o gene for reativado, eles retornam aos seus padrões normais de comportamento. Estudos populacionais e com familiares em humanos também implicaram o gene da MAO-A no comportamento anti-social ${ }^{2}$. Uma metanálise mostrou replicabilidade deste efeito de interação ${ }^{3}$.
O importante desafio para esta terceira geração de estudos genéticos sobre comportamento anti-social não é simplesmente identificar quais genes estão associados ao comportamento anti-social, mas também quais destes genes codificam transtornos cerebrais em grupos antisociais. Usando a MAO-A como exemplo, esta enzima metaboliza a serotonina, um neurotransmissor que está em níveis baixos em indivíduos anti-sociais. Homens com um polimorfismo comum (variante) no gene da MAO-A apresentam uma redução de $8 \%$ do volume da amígdala, giro do cíngulo anterior e córtex órbito-frontal (pré-frontal ventral) ${ }^{4}$. Essas estruturas cerebrais estão envolvidas na emoção e encontram-se comprometidas em indivíduos anti-sociais. Conseqüentemente, um dos genes associados a comportamento anti-social resulta em alterações estruturais em áreas cerebrais comprometidas em indivíduos anti-sociais - dos genes ao cérebro e ao comportamento anti-social.

\section{Dos genes ao cérebro e ao crime}

Então, como alguém evolui dos genes para o comportamento anti-social? Uma hipótese é de que as anormalidades genéticas resultem em anormalidades estruturais no cérebro, que resultam em anormalidades emocionais/cognitivas/comportamentais, as quais, por sua vez, predispõem ao comportamento anti-social. Há um número crescente de evidências para alterações cerebrais em grupos anti-sociais, com fortes evidências principalmente para o córtex pré-frontal ${ }^{5}$. Pacientes com transtornos neurológicos com danos no córtex préfrontal ventral exibem comportamento desinibido, do tipo psicopático, embotamento emocional e autonômico e tomada de decisão inadequada ${ }^{6}$. Pesquisas com 
ressonância magnética mostraram que indivíduos com transtornos de personalidade apresentam redução de $11 \%$ na substância cinzenta pré-frontal, junto com uma atividade reduzida durante um estressor social, provocando emoções "secundárias" de vergonha, constrangimento e culpa ${ }^{7}$. Indivíduos anti-sociais com menor quantidade de substância cinzenta também mostraram menor responsividade autonômica ao estresse. Diferentes paradigmas clínicos da neurociência estão começando a convergir para a mesma conclusão de que há uma significativa base cerebral no comportamento anti-social, e que esses processos neurocomportamentais são relevantes para entender a violência na sociedade cotidiana.

Prejuízos estruturais na área pré-frontal correspondem a prejuízos funcionais na área pré-frontal (ou seja, funcionamento reduzido) em uma ampla variedade de indivíduos anti-sociais. Verificou-se que assassinos mostram redução no metabolismo da glicose no córtex pré-frontal ${ }^{8}$. Essa disfunção também caracteriza especificamente infratores impulsivamente violentos, sugerindo que o córtex pré-frontal age como um "freio de emergência" para emoções desenfreadas geradas por estruturas límbicas. Estudos de neuroimagem são corroborados por achados de estudos neuropsicológicos, neurológicos e psicofisiológicos, indicando robustez dos achados.

Essas disfunções cerebrais são causadas por fatores ambientais ou por genes? Existe a hipótese de um papel significativo da genética por duas razões. Primeiro, a disfunção estrutural na área pré-frontal encontrada em indivíduos anti-sociais não foi responsabilizada por fatores ambientais para o comportamento anti-social (por exemplo: histórico de traumatismo craniano, maus tratos na infância) ou por abuso de álcool/drogas ${ }^{7}$. Segundo, imagens estruturais do cérebro a partir de estudos comportamentais e genéticos com gêmeos demonstraram que os genes explicam $90 \%$ da variação do volume de substância cinzenta pré-frontal em humanos ${ }^{9}$. Esses dois argumentos, em combinação, poderiam ser uma forte indicação de que as disfunções estruturais em anti-sociais apresentam uma significativa base genética, embora estudos futuros possam ainda identificar alguma relevância do ambiente.

\section{O papel do ambiente social}

Embora os genes provavelmente estejam implicados na causa do crime, processos psicossociais não podem ser descartados, podendo até ser essenciais. Influências ambientais no início do desenvolvimento poderiam alterar diretamente a expressão do gene, por sua vez alterando o funcionamento cerebral e resultando em comportamento anti-social. Influências ambientais precoces podem alterar a expressão gênica, o que então origina a cascata de eventos de comportamento cerebral destacados acima. O conceito é que, apesar de $50 \%$ da variação em comportamento anti-social ser genética na sua origem, os genes não são fixos, estáticos e imutáveis; influências psicossociais podem resultar em modificações estruturais no DNA que têm influências profundas no funcionamento neuronal e, em função disso, surgiria o comportamento anti-social.

$\mathrm{O}$ ambiente social pode interagir com fatores de risco genéticos e biológicos para comportamento antisocial de outras formas ${ }^{10}$. O comportamento violento e criminoso está exponencialmente aumentado quando combinado com fatores de risco sociais e biológicos. Estudos de diversos países demonstraram que complicações ao nascimento (incluindo anoxia neonatal, que causa lesão particularmente no hipocampo) interagem com ambientes familiares negativos (por exemplo: rejeição materna precoce da criança) para predispor à infração violenta na vida adulta. Também há evidências replicadas de que uma anormalidade no gene da MAO-A interage com maus tratos na infância para predispor ao comportamento anti-social em adultos ${ }^{2}$.

Processos sociais também podem interagir com fatores de risco genéticos e biológicos para gerar comportamento antisocial de diversas formas. A redução do metabolismo da glicose no córtex pré-frontal predispõe à violência em indivíduos com contextos familiares positivos. Baixa excitação psicológica está particularmente associada ao comportamento anti-social em indivíduos de contextos familiares positivos. Nesses casos, em que o indivíduo apresenta falta de fatores de risco sociais que o "empurrem" em direção ao comportamento anti-social, fatores biológicos têm um maior papel explanatório ${ }^{10}$. Em contraste, a associação entre comportamento anti-social e fatores de risco biológicos em indivíduos de contextos familiares negativos pode ser mais fraca porque as causas sociais do crime "camuflam" a contribuição biológica.

\section{Implicações do tratamento}

A biologia não é destino, e deve ser, em última análise, possível modular fatores de risco neurobiológicos. A questão essencial é: "Se os criminosos apresentam cérebros com defeito, como eles podem ser consertados?". Soluções definitivas poderiam ser naturais e surpreendentemente simples. Deficiência alimentar nos primeiros 3 anos de vida tem sido associada a comportamento anti-social a longo prazo durante a infância e final da adolescência ${ }^{11}$. O controle do QI abole essa relação, sustentando o modelo de que alimentação deficiente leva a funcionamento cerebral 
deficiente, resultando em disfunções neurocognitivas que predispõem ao comportamento anti-social. O óleo de peixe é rico em ômega-3, um ácido graxo de cadeia longa que compõe $40 \%$ da membrana celular, e a suplementação alimentar foi associada a aumento de QI e redução de comportamento anti-social grave em detentos12. Programas de prevenção que manipulam a alimentação nas fases iniciais da vida resultaram em redução de delinqüência ${ }^{13}$ e criminalidade $^{14}$. Manipulações ambientais podem, em tese, reverter fatores de risco cerebrais para o crime.

Uma abordagem alternativa é modular as anormalidades dos neurotransmissores produzidas por anormalidades nos genes. Genes que regulam o transporte da serotonina foram recentemente associados a comportamento anti-social e agressivo em crianças e adultos. Uma vez que indivíduos anti-sociais/agressivos apresentam baixos níveis de serotonina, medicações que aumentam a disponibilidade de serotonina (como inibidores seletivos da recaptação de serotonina), devem diminuir o comportamento anti-social se houver uma conexão causal. Há evidências que apóiam essa previsão em crianças e adultos agressivos ${ }^{15}$.

\section{Implicações neuroéticas e neurolegais}

Apesar dessas evidências positivas, permanece o fato de que a sociedade reluta em usar medicação para tratar comportamento agressivo e anti-social, ao mesmo tempo em que se sente confortável para medicar outras condições comportamentais. Paradoxalmente, já que as influências comportamentais influenciam a expressão do gene, nossa constituição está em constante mutação, quer queiramos ou não. A sociedade deve "agarrar o touro biológico à unha" para extinguir o crime e a violência e reduzir o sofrimento? Ou, ao contrário, deve fingir não ver o novo conhecimento clínico em neurociência e proibir a interferência com a essência biológica da humanidade, mesmo se isso resultar em vidas perdidas que poderiam ter sido salvas por esforços de prevenção biológica?

Outra preocupação adicional é a que trata de responsabilidade e punição. Se um assassino sofre disfunções cerebrais que o predispõem a cometer violência impulsiva, deveremos responsabilizá-lo inteiramente por seu comportamento? Pesquisas pioneiras estão elucidando o mecanismo neural que auxilia na tomada de decisão moral ${ }^{16-18}$. De uma perspectiva de julgamento moral, dadas as evidências de que os circuitos neurais subjacentes ao sentimento moral e tomada de decisão estão prejudicados nas populações anti-sociais ${ }^{5}$, esses indivíduos são tão capazes quanto o resto de nós de saber - e fazer - o que é certo? Um psicopata pode saber a diferença legal entre o certo e o errado, mas eles têm o sentimento do que é certo e do que é errado? Acredita-se que as emoções sejam centrais ao julgamento moral, oferecendo a força de impulsão para agir moralmente. Neste contexto, até que ponto é moral punirmos criminosos tão severamente quanto o fazemos? Por outro lado, não há perigos significativos se afrouxarmos nosso conceito de responsabilidade? O próprio conceito "dos genes ao cérebro e ao comportamento anti-social" suscita questões neuroéticas que precisam ser discutidas para que a ciência preventiva possa progredir.

Uma nova geração de pesquisas em neurociência clínica que engloba imagens cerebrais e genética molecular está originando o conceito de que genes específicos resultam em disfunções cerebrais funcionais e estruturais que predispõem ao comportamento antisocial, violento e psicopata. Um próximo passo essencial para testar a hipótese "dos genes ao cérebro e ao comportamento anti-social" é conduzir pesquisa genética molecular e de neuroimagem na mesma população para identificar os genes codificando tanto as anormalidades de estrutura/função cerebral quanto o comportamento anti-social. O próximo passo empírico é descobrir se indivíduos psicopatas e anti-sociais evidenciam processamento anormal de dilemas morais. Como lidaremos com esse novo conhecimento em nível social e legal é um significativo desafio neuroético. Quanto mais aprendemos sobre as causas neurobiológicas do crime, mais questões complexas surgem a respeito de culpabilidade, punição e livre arbítrio. Os desafios futuros científicos e neuroéticos para o campo emergente de neurocriminologia podem ser melhor enfrentados através de pesquisa multidisciplinar integradora que associe teorias macrossociais tradicionais (enfatizando amplos construtos sociais) com novas perspectivas da neurociência clínica e social para entender melhor, e por fim prevenir, o comportamento anti-social em crianças e o crime em adultos.

\section{Referências}

1. Moffitt TE. The new look of behavioral genetics in developmental psychopathology: Gene-environment interplay in antisocial behaviors. Psychol Bull. 2005;131:533-54.

2. Caspi A, McClay J, Moffitt TE, Mill J, Martin J, Craig IW, et al. Role of genotype in the cycle of violence in maltreated children. Science. 2002;297:851-4.

3. Kim-Cohen J. Caspi A, Taylor A, Williams B, Newcombe R, Craig $\mathrm{IW}$, et al. MAOA, maltreatment, and gene-environment interaction predicting children's mental health: new evidence and a metaanalysis. Mol Psychiatry. 2006;11:903-13.

4. Meyer-Lindenberg A, Buckholtz JW, Kolachana B, Hariri AR, Pezawas L, Blasi G, et al. Neural mechanisms of genetic risk for impulsivity and violence in humans. Proc Nat Acad Sci U S A. 2006;103:6269-74.

5. Raine A, Yang Y. Neural foundations to moral reasoning and antisocial behavior. Soc Cogn Affect Neurosc. 2006;1:203-13. 
6. Damasio AR. Descartes' error: emotion, reason, and the human brain. New York: GP Putnam's; 1994.

7. Raine A, Lencz T, Bihrle S, LaCasse L, Colletti P. Reduced prefrontal gray matter volume and reduced autonomic activity in antisocial personality disorder. Arch Gen Psychiatry. 2000;57:119-27.

8. Raine A, Buchsbaum M, LaCasse L. Brain abnormalities in murderers indicated by positron emission tomography. Biol Psychiatry. 1997;42:495-508.

9. Thompson PM, Cannon TD, Narr KL, van Erp T, Poutanen VP, Huttunen $M$, et al. Genetic influences on brain structure. Nat Neurosci. 2001;4:1253-8.

10. Raine A. Biosocial studies of antisocial and violent behavior in children and adults: a review. J Abnorm Child Psychol. 2002;30:311-26.

11. Liu J, Raine A, Venables PH, Mednick SA. Malnutrition at age 3 years and externalizing behavior problems at ages 8, 11 and 17 years. Am J Psychiatry. 2004;161:2005-13.

12. Gesch CB, Hammond SM, Hampson SE, Eves A, Crowder M J. Influence of supplementary vitamins, minerals and essential fatty acids on the antisocial behaviour of young adult prisoners: randomised, placebo- controlled trial. Br J Psychiatry. 2002;181:22-8.

13. Olds D, Henderson CR Jr., Cole R, Eckenrode J, Kitzman H, Luckey
D, et al.. Long-term effects of nurse home visitation on children's criminal and antisocial behavior: 15-year follow-up of a randomized controlled trial: reply. JAMA. 1999;281:1377.

14. Raine A, Mellingen K, Liu JH, Venables PH, Mednick SA. Effects of environmental enrichment at 3-5 years on schizotypal personality and antisocial behavior at ages 17 and 23 years. Am J Psychiatry. 2003;160:1627-35.

15. Connor DF, Boone RT, Steingard RJ, Lopez ID, Melloni RH. Psychopharmacology and aggression: II. A meta-analysis of nonstimulant medication effects on overt aggression-related behaviors in youth with SED. J Emot Behav Disord. 2003;11:15768.

16. Greene JD, Sommerville RB, Nystrom LE, Darley JM, Cohen JD. An fMRI investigation of emotional engagement in moral judgment. Science. 2001:293:2105-8.

17. Moll J, de Oliveira-Souza R, Eslinger PJ, Bramati IE, MourãoMiranda J, Andreiuolo PA, et al. The neural correlates of moral sensitivity: A functional magnetic resonance imaging investigation of basic and moral emotions. J Neurosci. 2002;22:2730-6.

18. Moll J, de Oliveira-Souza R, Moll FT, Ignacio FA, Bramati IE, Caparelli-Dáquer EM, et al. The moral affiliations of disgust: a functional MRI study. Cogn Behav Neurol. 2005;18:68-78. 